\title{
Decoding the effects of a product's cast shadow in brand advertising
}

\author{
Nazuk Sharma \\ Fairfield University, nsharma@fairfield.edu
}

Follow this and additional works at: https://digitalcommons.fairfield.edu/business-facultypubs

Copyright 2018 Emerald Publishing Limited

The author post-print has been archived here with permission from the copyright holder.

\section{Peer Reviewed}

\section{Repository Citation}

Sharma, Nazuk, "Decoding the effects of a product's cast shadow in brand advertising" (2018). Business Faculty Publications. 224.

https://digitalcommons.fairfield.edu/business-facultypubs/224

\section{Published Citation}

Sharma, Nazuk. "Decoding the effects of a product's cast shadow in brand advertising." Journal of Product \& Brand Management 27, no. 2 (2018): 103-114. https://doi.org/10.1108/JPBM-05-2016-1190

This item has been accepted for inclusion in DigitalCommons@Fairfield by an authorized administrator of DigitalCommons@Fairfield. It is brought to you by DigitalCommons@Fairfield with permission from the rightsholder(s) and is protected by copyright and/or related rights. You are free to use this item in any way that is permitted by the copyright and related rights legislation that applies to your use. For other uses, you need to obtain permission from the rights-holder(s) directly, unless additional rights are indicated by a Creative Commons license in the record and/or on the work itself. For more information, please contact digitalcommons@fairfield.edu. 


\title{
Decoding the effects of a product's cast shadow
}

\begin{abstract}
Purpose - This research investigates the impact of product shadows on consumer ad and brand perceptions.
\end{abstract}

Design/methodology/approach - Three experimentally designed studies demonstrate how presence (vs absence) of a product's cast shadow implicitly influences not only ad assessments, but also brand evaluations.

Findings - The presence of a product's cast shadow in a visual frame subliminally complements abstract processing of an experiential brand, thus improves its brand evaluation, through a greater ease of product evaluation. In contrast, the same product shadow hurts a functional brand's concrete gestalt by acting as visual noise, and lowering the ease of product evaluation.

Research limitations/implications - Current studies make an initial attempt to explore the relationship between product shadows and consumer perceptions. Future studies may be designed to test the effects of color, visual complexity and brand familiarity together with product shadows.

Practical implications - This research shows that subtle visual elements such as product shadows should not be ignored by brand managers. They influence consumer perceptions automatically, and differently, depending upon a specific brand-concept (i.e. experiential vs functional). Current findings also present cost implications with respect to limited and competitive advertising space.

Originality/value - This paper opens up research avenues in the domain of shadow based advertising, while extending prior research on brand-image communication. It provides a deeper understanding of the underlying processes (construal, signal efficacy and processing fluency) that influence ad and brand perceptions, when a product is showcased with its shadow in a promotional frame.

Keywords Product's cast shadow, Brand-concept, Brand-image, Construal, Processing fluency

Paper type Research paper 


\section{Decoding the effects of a product's cast shadow}

Firms use specific brand-concepts such as experiential (pleasure-stimulating), symbolic (self/group-associating) or functional (problem-solving) to foster brand-images in the minds of consumers (Keller, 1993; Keller et al., 2011; Park et al., 1986). A brand-concept is defined as "a firm selected brand meaning derived from basic consumer needs (functional, symbolic and experiential)" (Park et al., 1986, p. 136). Advertising acts as a strong medium for communicating such specific brand-associations, and translating a firm formulated brand-concept to a consumer perceived brand-image (Keller, 1993, Meenaghan, 1995). Keller (1993, p. 3) defines brand-image as "consumer perceptions about a brand, as reflected by brand associations held in consumer memory". Brand promotions help transform a brand-concept to a brand-image, through memory integration of all the brand related information acquired by a consumer (Clayton and Heo, 2011).

According to the Associative Networks Memory (ANM) model, an overall brandimage gets linked to brand-specific attributes, benefits, and attitudes through associational paths in consumer memory (Keller, 1993). It is therefore recommended that brands use a single, consistent, and coherent brand-concept while advertising, to avoid conflicting consumer brand associations (Martin and Stewart, 2001; Park et al., 1991, Thorbjørnsen, 2005). Once chosen by a firm, an integrated brand-concept can determine a brand's performance across product categories, product life cycles, and even future brand extensions (Park et al., 1991). This brand-image, in turn becomes a powerful predictor of the Customer Based Brand Equity (CBBE), which further manifests in their brand purchase behaviors (Faircloth et al., 2001). Therefore, promotion strategies geared towards maintaining this brand-concept to brand-image communication consistency becomes critical.

Prior research documents the role of verbal and visual (or pictorial) ad elements (such as brand name, brand claims, and product's picture/s), as well as the organization, layout and size manipulations of these ad elements on brand evaluations (Edell and Staelin, 1983; Janiszewski, 1990; Pieters and Wedel, 2004). However, the impact of the presence of a product's shadow in an ad frame on brand perceptions, is yet to be examined. Brands such as Apple, Omega and Samsung can be commonly seen using product shadows as a part of their visual promotions (see Appendix 1). The aim of the current research is to assess how such subtle visual ad elements such as product shadows influence a consumer's perceived brand-image, in addition to the overall ad evaluations.

A psychological brand-image can be formed in the consumer's mind even before his/her first actual product experience, i.e. through brand advertising. These brand associations are not always product-specific, but rather carefully modeled through marketing activities such as advertising and promotions (Dobni and Zinkhan, 1990; Keller et al., 2011, Meenaghan, 1995). In fact, many brand promotions do not even show the product, but foster brand-images through completely different ad elements such as metaphorical claims and pictures, or celebrity shots that match the product attributes to be conveyed (Ang and Lim, 2006; Till and Busler, 2000). Therefore, it is important to pay 
attention to all the elements being incorporated in a brand ad, to ensure that a specific brand-concept is communicated effectively and consistently.

In this research, it is examined if something as subtle and peripheral as a product's shadow affects this brand-concept to brand-image translation efficacy. More specifically, this research looks at experiential and functional brand-concepts, together with the product's picture presented with (or without) its shadow in a promotional frame, in examining how it impacts consumers' ad and brand evaluations ${ }^{1}$. A qualitative analysis of brand promotions with product visuals reveals an indiscriminate use of product shadows. Sometimes a same brand is seen employing product shadows in a few frames, and no such elements in others (e.g. Apple). Amongst competitor brands, Apple uses product shadows to a much greater extent in its product promotions, compared to Android (see Appendix 1). This random use of product shadows in brand advertising necessitates a call for identifying the influence of these elements on ad and brand perceptions. Additionally, given the importance of brand-concept to brand-image communication efficiency in brand advertising, it is relevant to systematically investigate the conditions under which it may be beneficial to employ product shadows, in contrast to the conditions under which it may not.

This research draws upon the understanding of object shadows from visual art and cognition literatures to propose that the presence of a product's shadow enhances global, holistic and abstract ad processing, while its absence facilitates concrete ad construals, that entail a more localized and detailed visual processing of the advertised product (Dee and Santos, 2011; Mamassian, 2004; Liberman et al., 2007). Additionally, given that shadows are processed subliminally, as they are natural to any object viewed under a light source, it is likely that such construal facilitations occur implicitly i.e., without a consumer's conscious awareness (Wedel and Pieter, 2012). To test such automatic construal associations of products presented with or without shadows, a first study is designed as an Implicit Association Task, IAT (Greenwald et al., 2003).

A second study tests for differences in ad and brand evaluations based on the presence (vs absence) of a product's shadow in an experiential (vs a functional) brand context. It is proposed that the overall ad ratings and brand perceptions for an experiential brand will be higher when the product is presented with its shadow in the frame. This is due to the complementarity between the holistic processing of the product's picture alongside the product's shadow and the inherently abstract brand claims of an experiential brand (Lee and Labroo, 2004). In contrast, ad ratings and brand assessments are proposed to be lower in the presence of a product's shadow (vs absence) for a functional brand, due to the need for concrete, localized processing for such brands (Liberman and Trope, 1998). Shadows are proposed to act as visual noise for such gestalts and hence, lower the consumer evaluations (Rensink and Cavanagh, 2004). However, given the implicit nature of shadow processing, it is expected that this study would not reveal direct effects on the gestalt measure, so as to test it as a mediator (as identified in the literature and evidenced by the IAT in study 1 ).

However, even though product shadows may be implicitly assimilated towards construals, it is suggested that a more downstream construct of processing fluency be used 
as a surrogate, explicit process to understand how shadows affect ad and brand perceptions. This is tested in a third study. In the case of an experiential brand frame, the overall ease of product evaluation should be higher in shadow's presence (vs absence) due to a greater fluency of the brand-image and the shadow's gestalt. On the other hand, ease of product evaluation should be lower in shadow's presence for a functional brand, since it acts as optical noise in the frame. Therefore, ease of product evaluation is finally tested as a mediator to the proposed effects for experiential (vs functional) brands in study 3 .

To the best of the literature based knowledge, this research makes a first attempt to explore the effects of product shadows in promotional frames. Theoretical frameworks of Associative Networks Memory Model (ANM), Construal Level Theory (CLT), Signal Detection Theory (SDT), and Processing Fluency Model (PFM) have been applied towards reasoning and building rationales for the hypotheses. In addition to opening a stream of research on shadow based advertising, this research also extends the understanding of specific brand scenarios, where the use of product shadows can complement (i.e. experiential), compared to where their use can mar a brand-image (i.e. functional). This research carefully considers subliminal aspects of shadow processing, and crafts studies with strict controls to demonstrate the proposed effects. Additionally, this research makes a significant contribution to the managerial incorporation and strategic use of product shadows as ad elements towards successful brand-concept to brand-image translation.

\section{Shadows and construals}

Cast shadows (formed when an object blocks a surface from a light source) are helpful in determining an object's shape/form, structure, orientation, and spatial position in a visual frame (Cavanagh and Leclerc, 1989; Dee and Santos, 2011; Mamassian et al., 1998). Cast shadows act as useful cues in providing information about $a$ ) the focal object, $b$ ) the light source, and $c$ ) the properties of the surface on which it is cast (Cavanagh and Leclerc, 1989; Dee and Santos, 2011; Mamassian et al., 1998). Anatomically, cast shadows correspond to low spatial frequency content, i.e. visual information that is assimilated through a coarse scene abstraction (Casati, 2004; Dee and Santos, 2011; Mamassian, 2008).

In visual marketing, a distinction is made between the foveal and peripheral visions, such that the former is slow, localized, detailed, and sensitive to high spatial frequencies, while the latter is more fast-paced, coarse, and prone to low spatial frequencies (Wedel and Pieters, 2012). This research focuses on cast shadows which are processed using a rapid interpretation system (or an early level system), whereby vision attempts to extract broadlevel or coarse information regarding the visual field as quickly as possible i.e. within 100 milliseconds of the stimulus encounter (Dee and Santos, 2011; Rensink and Cavanagh, 2004). Given that shadow-abstraction follows a quick gist extraction process based on this rapid interpretation system, it is more likely to be processed by the peripheral vision, which as mentioned is sensitive to the low spatial frequency content like shadows.

As per Construal Level Theory (CLT), abstract construals extract gist from the available information, while ignoring the incidental, lower-level details (Liberman et al., 2007; Trope and Liberman, 2010). Abstract construals are more general, superordinate, 
and schematic, while concrete construals are specific, subordinate and localized (Liberman and Trope 1998; Kardes et al., 2006). Therefore, based on the nature of object shadows as low spatial frequency content, and the type of visual system invoked for processing them (i.e. peripheral), it is suggested that the presence of a product's cast shadow in an ad frame would facilitate abstract or gestaltic processing. Consumers would respond more favorably to product shadows in a global, holistic or an abstract construal (Trope and Liberman, 2010).

Literature on object shadows also documents two major perceptual difficulties in shadow processing: $a$ ) shadow-segregation and $b$ ) shadow-correspondence (Dee and Santos, 2011). An observer has to visually recover the object from the shadow's substance and outline, and distinguish it from the real object (shadow-segregation), while also being able to unambiguously anchor that shadow back to its appropriate caster (shadowcorrespondence) (Dee and Santos, 2011)2. For accurate overall interpretations, viewers have to distinguish the shadow boundaries from the casting object, and discount them to reduce their nuisance value in many cases (Cavanagh and Leclerc, 1989). For instance, Rensink and Cavanagh (2004) find that a deviation from natural occurrences with respect to shadows increases response times in visual search tasks e.g. when the shadows are presented upside-down vs upright.

Especially in detailed oriented tasks like visual search, object recognition and shape recovery estimations, cast shadows act as noise and reduce performance (Cavanagh and Leclerc, 1989; Rensink and Cavanagh, 2004). Hence, presence of cast shadows could hurt concrete construals that require a relatively stronger focus on the individual, incidental details than the overall gist (Liberman and Trope, 1998). Cast shadows may be anatomically congruent with abstract processing, but their presence acts as optical noise in a concrete construal, where effort needs to be expended in discounting them. Therefore, in line with the tenants of Construal Level Theory (CLT), consumers would respond less favorably to product shadows in detail-seeking, concrete construals.

\section{Implicit processing of shadows}

Shadows are naturally occurring to any object presented under a light source, and theoretically cannot exist without a casting objects (i.e. they are con-substantial) (Mamassian, 2004; Mamassian, 2008). Additionally, as mentioned before, they are processed as quickly as within 100 milliseconds of the stimulus onset (Rensink and Cavanagh, 2004). Therefore, the human visual system has adapted towards a fast-paced processing of object shadows, which it encounters frequently in everyday life (Dee and Santos, 2011). In most cases, shadow registration does not depend upon an observer's conscious awareness, i.e. they are processed subliminally (Dee and Santos, 2011). Given that they are processed using the peripheral vision, it is likely that they influence perceptions implicitly (Wedel and Pieters, 2012). This is because the human visual processing system has leant to assimilate them naturally, and quickly (Dee and Santos, 2011; Mamassian, 2004). 
Art and visual perception literatures also document that observers remain insensitive to violations of optical physics depicted through inconsistent shadows (Casati, 2004; Jacobson and Werner, 2004; Mamassian, 2008). However, they still impact an observer's perceptions, and are able to portray the artist's intent through the painting meaningfully (Casati, 2004; Mamassian, 2008). Therefore, even though subliminal, visual processing of object shadows could impact the higher-level mental perceptions, and evaluations of an observer. In fact, Castiello, Paulignan and Jeannerod (1991) provide evidence that a sensory modality can work independent of the overt perceptual experience of a stimulus. At the same time, information attained from a sensory modality can be used towards higher-level reasoning, judgments and performance evaluations, albeit not always consciously. Hence, depending upon the context i.e. abstract (or concrete), visual abstraction (or discounting) of shadows can impact higher-level mental judgements, even though implicitly (Wedel and Pieters, 2012).

Based on the discussion in the last section, it was proposed that shadows complement abstract processing, but hurt concrete construals. However, the subliminal processing of product shadows in ad frames creates an impediment to measuring a consumer's construal mappings explicitly. An explicit probing of the role of a product's shadow in determining consumers' evaluations may also lead to demand biases (such as hypotheses guessing). Therefore, in order to test such automatic construal associations of products presented with (or without) shadows, the first study is designed under the strict guidelines of an Implicit Association Task, IAT (Greenwald et al., 2003). Such tests are resistant to any introspective access to the associations being measured.

Implicit tests have been used in the social and behavioral sciences to gauge associations prone to response biases (e.g. racial and gender biases) (Greenwald et al., 1998). For example, researchers have used target concepts such as black/white and attributes such as pleasant/unpleasant to uncover subliminal racial biases (Greenwald et al., 1998). Respondents were asked to quickly categorize images (e.g. African-American or European-American) under the combined target-attribute pairs (i.e. blackunpleasant/white-pleasant or white-unpleasant/black-pleasant). A measure of implicit attitude or mental association strength is computed from the performance speeds of classifications using these target-attribute pairs. For instance, if someone holds a racial prejudice, he/she may classify an African-American individual's image, fairly quickly towards the 'black-unpleasant' pair (or take longer to classify the same image to the 'blackpleasant' pair).

A typical IAT measures the strength of differential association of two target-concepts with an attribute, while avoiding any demand effects (Greenwald et al., 2003). Since it measures the strength of memory associations (i.e. closeness in terms of mental concepts, and not causations), it makes a fitting procedure for testing brand associations following the ANM (Associative Networks Memory) model, for decoding the consumer perceived brand-images as fostered through brand advertising (Keller, 1993). In this research, an IAT has been used to capture the mental closeness of abstract and concrete construals as target-concepts to product pictures containing shadows and no-shadows as attributes, in the consumers' minds. The strength of association for product pictures with (and without) 
shadows as attributes to abstract (vs concrete) construals as the target-concepts, is determined through differences in response latencies of quick classifications to the paired target-concept and attribute tags.

Specifically, it is proposed that a consumer would take longer to correctly classify product pictures (randomly presented one at a time, with and without shadows) to incompatible target-attribute pairs (concrete/shadow; abstract/no-shadow) compared to compatible target-attribute pairs (concrete/no-shadow; abstract/shadow) (see Appendix 2). The difference between the response latencies for correct classifications to incompatible and compatible groupings or tags provides a strength measure for the implicit, mental associations among product shadow and the corresponding construal in the consumer's memory. Therefore:

H1: The strength of association based on the difference between response-latencies of correctly classifying product pictures with and without shadows, to incompatible target-attribute pairs (concrete/shadow, abstract/no-shadow) and compatible target-attribute pairs (concrete/no-shadow, abstract/shadow) will be positive.

\section{Aligning the brand-concept with the product shadow}

An experiential brand intends to stimulate sensory pleasure by accentuating the more desirable product aspects such as its overall look, shape/form, design and aesthetics (Berlyne, 1974; Park et al., 1986). Such aspects are considered stimulating in that they involve higher-order, feature interactions, as a part of the overall product gestalt (Holbrook, 1986). A functional brand in contrast, highlights the lower-order, feasible product attributes such as the product's size and performance related attributes (Keller et al., 2011). Construal Level Theory (CLT) differentiates between these desirable and feasible aspects, referring to the former as higher-order, schematic or abstract, and the latter as lower-order, vivid or concrete (Kardes et al., 2006; Liberman and Trope, 1998; Liu, 2008). Therefore, if an experiential brand-concept is to be communicated through an ad effectively, the overall ad processing as well as brand evaluation should be facilitated by the complementing, abstract, low spatial frequency element, i.e. product shadow. Product shadow's presence would enhance the desirable aspects of an experiential brand such as the product's form and aesthetics by contrasting it from the background of the ad frame (Cavanagh and Leclerc, 1989; Mamassian, 2008). Therefore,

H2-H3. The overall ad ratings (H2) and brand evaluations (H3) for an experiential brand will be higher when the product is presented with its cast shadow in the ad frame, than without it.

On the other hand, a functional brand's assessment should be better in a more detailed, or concrete construal i.e., without any shadows in the ad frame (Keller et al., 2011; Liberman et al., 2007). Product shadows would in fact act as optical noise, and need to be discounted in a functional brand's promotional context. As per Signal Detection Theory (SDT), there should be minimal noise in a channel for an effective signal transmission, especially in quick evaluative frames such as brand advertisements (Shannon, 1949). If a 
product is presented with its cast shadow in the ad frame, the overall evaluations of a functional brand would decline since the consumer would have to segregate shadow from the product's form to grasp its lower-level, feasible details in forming an evaluative judgement (shadow-segregation, Dee and Santos, 2011). Thus,

H4-H5. The overall ad ratings (H4) and brand evaluations (H5) for a functional brand will be lower when the product is presented with its cast shadow in the ad frame, than without it.

\section{Processing fluency: a surrogate mediator}

To better understand the underlying processes working towards differential brand evaluations, based on a specific brand-concept (experiential vs functional) and presence (vs absence) of a product's cast shadow, an evidence of mediation based on the construal mapping is needed. However, due to the peripheral and implicit processing of shadows as ad elements (as evidenced by the need to conduct an IAT), processing fluency can still be tested as a potential mediator to the holistic ad and brand assessments. Additionally, while direct probing of shadows as influencers could create demand biases, processing fluency of all the ad elements (including the brand claims, as well as the product's picture with or without shadow) can be used to comprehend the combined effect of brand-concept and product shadow on ad and brand evaluations ${ }^{3}$.

In other words, without pointedly asking for the impact of a product's shadow on a consumer's overall brand-image perceptions, this downstream measure of fluency can unobtrusively provide an understanding of the underlying mechanism for changes in consumer evaluations. If the presence of a product's shadow in the ad frame implicitly affects a brand-image, this impact should still manifest in the consumers' ease of product evaluation in shadow's presence (vs absence). However, unlike implicit construal associations, fluency of processing can be probed for explicitly as it asks consumers how easy or difficult do they find evaluating the product based on the ad (rather than if product shadows are affecting their brand perceptions).

Processing Fluency Model (PFM), suggests that advertising exposures that enhance the fit or complementarity, lead to more favorable brand attitudes (Lee and Aaker, 2004; Lee and Labroo, 2004; Lee, 2002). For an experiential brand, due to a fit between the focus on desirable product aspects, and abstract elements such as a product shadow, processing fluency should be higher. If an experiential brand-concept is to be communicated through both verbal and visual ad elements, the overall ease of product evaluation (i.e. processing fluency) should be facilitated by complementing, abstract elements like product shadows (Landwehr et al., 2011; Lee and Labroo, 2004; Song and Schwarz, 2008a, Sheng Goh et al., 2013). This enhanced fluency is proposed to mediate the effects of presence (vs absence) of product shadow in an experiential brand's frame on the overall ad and brand evaluations. Hence, 
H6-H7. The effect of a product's cast shadow on the overall ad ratings (H6) and brand evaluations (H7) for an experiential brand will be mediated by an improved processing fluency in the shadow's presence (vs absence).

In contrast, ease of product evaluation should be lower in the presence of a product's shadow (compared to its absence) in the functional brand's ad frame. As discussed before, a shadow would act as visual noise in the functional brand's frame, and hence decrease the overall fluency of processing of the ad elements (Landwehr et al., 2011; Sheng Goh et al., 2013; Song and Schwarz, 2008b). This lowered fluency would then in turn reduce the ad evaluations as well as the brand perceptions for a functional brand. Therefore,

H8-H9. The effect of a product's cast shadow on the overall ad ratings (H8) and brand evaluations (H9) for a functional brand will be mediated by a lowered processing fluency in the shadow's presence (vs absence).

\section{Method}

\section{Study 1}

In study 1, 155 respondents ( $M_{\text {age }}=33,39 \%$ females) from Amazon's MTurk (located within the U.S geographic) participated for compensation (\$0.40). MTurk provides access to a wider demographic, thus lending higher external validity (Goodman and Imrak, 2013). The survey was designed on Socialsci.com, as it provides a flexible framework to run multiple trials for an IAT (Greenwald et al., 2003). The IAT employed 'abstract'/'concrete' as the target-concepts and 'shadow'/'no-shadow' as the attribute tags. The pictures to be classified under the target-concepts were adapted from established gestalt-completion tests (Trope and Liberman, 2010). Three greyscale pictures were chosen under each target-concept such that there was one concrete picture corresponding to every abstract picture. Participants were provided with definitions for the target-concepts (abstract and concrete) to ensure proper interpretation while classifying (Trope and Liberman, 2010). Greyscale product images (to avoid any color confounds) were selected from different product categories, and cropped for shadow using Photoshop. Each product had a shadow and a no-shadow version to be classified (see Appendix 2).

In a 2 (Initial target-concept presentation order: abstract on left and concrete on right vs concrete on left and abstract on right) X 2 (Pairing order: compatible before incompatible vs incompatible before compatible) between-subjects design, each respondent quickly classified a randomly presented picture to target, attribute and target-attribute combined tags in a series of trials. This design allowed testing for any learning-based, or order effects that could potentially bias the IAT strength measure (Greenwald et al., 1998). In the first set of trials (stage 1), respondents practiced discriminating randomly presented gestalt pictures quickly to target-concept tags (abstract vs concrete) using the keys, ' $e$ ' (for left) and ' $i$ ' (for right) (see Appendix 3). In stage 2, they performed an attribute discrimination practice task by sorting product pictures to shadow or no-shadow tags using the same keys. Following practice, two combined classification tasks were performed 
where the target-concept and attribute tags were presented together, with a random mix of gestalt and product pictures to classify (stages 3 and 4). Then, the order of target-concept tags was reversed, and participants practiced sorting the gestalt pictures again (stage 5). In the last stages (6 and 7), with the target-concept positions reversed, and the attribute tags held constant in their positions, participants categorized all the pictures one last time. The response and error latencies (in milliseconds) were recorded by the background software for each trial (Greenwald et al., 1998; Nosek et al., 2005).

\section{Hypothesis testing: $H 1$}

After considering multiple candidate measures, the ' $D$ ' measure was finalized for testing hypothesis 1 (Greenwald et al., 2003). D calculates a mean difference from the response latencies of classifying towards incompatible and compatible target-attribute pairs, and adjusts them for the underlying variability (Greenwald et al., 2003; see Appendix 3). Eliminating respondents for missing data, and time spent greater than 10 minutes, the final count of respondents analyzed was 144 (as per criteria defined by Greenwald et al., 2003). Latencies captured in the initial, combined classification trials (stages 3 and 4) were subtracted from the latencies captured at the latter stages of the IAT (stages 6 and 7) for each respondent. In addition, the count of incorrect responses was used to penalize the mean response latency ("stage mean $+2 * S D$ of correct responses", Greenwald et al., 2003). Hence, controlling for the number of incorrect classifications, a final $D$ value was calculated by adjusting the mean response latency difference for inclusive standard deviations (see Appendix 3 for calculations).

The mean effect size when the compatible pairs were followed by the incompatible pairs was positive $(D=0.19)$, i.e. it took longer time for respondents to classify images when the target-attribute tags were incompatible (See Table |). Since the compatible pairs came after the incompatible pairs in the other set of trials, the mean response latency difference was negative $(D=-0.07)$. Therefore, using absolute values, the overall mean effect size was found to be positive, and statistically different from zero $\left(D_{\text {absolute }}=0.13\right.$, SD $=0.70, t(143)=2.277, p=0.024)$ (See Table I) (Lee et al., 2014). This value corresponds to a small effect size ( $d=0.10$ to $0.20, \alpha=0.05$, Cohen, 1992). Given the rapid interpretation or early system process involved in shadow processing, a small effect size was reasonable to expect (Cohen, 1992). Hence, $H 1$ was supported.

\section{PLACE TABLE | ABOUT HERE}

A test of mean difference on $D_{\text {absolute }}$ using initial target concept presentation orders was not significant $\left(M_{\text {abstract-left }}=0.15\right.$ vs $\left.M_{\text {concrete-left }}=0.12, t(142)=0.228, p=0.82\right)$. Mean difference between the pairing orders was also not significant $\left(M_{\text {compatible-first }}=0.19\right.$ vs $\left.M_{\text {incompatible-first }}=0.07, t(142)=1.008, p=0.32\right)$. Hence, the effect size measure $(D)$ was not influenced by any specific presentation order or learning effects. After finishing the IAT, subjects $(n=139$, after eliminating for missing data) were also probed explicitly for their perceptions regarding products presented with shadows in ad frames, using some semantic scale measures (bad/good, unnecessary/necessary, useless/useful, and unpleasant/pleasant). A one sample t-test on the average score $(\alpha=.86)$ revealed that the general perceptions 
regarding products presented with shadows were positive $(t(138)=6.97, p<0.01)$. Overall, findings from study 1 reveal that consumers implicitly associate product pictures with shadows closely to abstract construals in their mental representation. On the other hand, they closely associate product images without shadows to concrete construals in their network of memory associations. But, when probed for explicitly, there is a significant overall positive inclination towards products presented with their shadows in an ad frame.

\section{Study 2}

Study 2 attempts to test hypotheses $H 2$ to $H 5$ and incorporates an explicit construal measure to retest if the shadow processing occurs implicitly. Two pre-tests followed by a main study, were conducted using MTurk (U.S geographic). Participants were only allowed to take part in one of these studies, using their MTurk IDs as a screening criteria (since the pretested stimuli was to be employed for the main study). Pretest 1 consisted of only the brand's name (fictitious, to avoid any brand equity effects) and the product's picture, with or without the shadow as the between-subjects factor. For the stimuli, a portable music speaker was chosen as it could qualify for both experiential and functional brand aspects. The speaker was photographed under natural sunlight against a white background to avoid any confounds, and the picture was grey-scaled and cropped for shadow (see Appendix 4).

The aim of pretest 1 was to gauge if there were any evaluative differences in ad or brand perceptions, based on the shadow's presence versus absence (i.e. without any specific brand- concept manipulations through the verbal claims). Pretest 2 employed an equal mix of experiential and functional brand claims, in addition to the ad elements presented in pretest 1 . The aim of this second pretest was: $a$ ) to test if shadows influence brand perceptions independent of verbal claims that are equally experiential and functional, and $b$ ) to test if the chosen experiential and functional claims were indeed conveying the respective brand images orthogonally.

\section{Pretests}

A first pretest consisted of an ad with only the brand's name (fictitious, $M_{\text {familiarity }}=1.27$, very low) and the product's picture, following a single factor (product's shadow: present vs absent), between-subjects design $\left(n=51, M_{\text {age }}=33,41 \%\right.$ females, compensation $\left.=\$ 0.15\right)$. This pretest followed one factor, two-level (product's shadow: present vs absent), between-subjects design. An ANOVA did not present any statistical differences on a 5-point ad rating measure - very bad/very good $\left(M_{\text {shadow }}=2.96\right.$ vs $M_{\text {no-shadow }}=3.19, F(1,49)=0.92$, $p=0.34$ ) or on the 7-point, overall brand evaluation score - bad/good, dislike/like, unfavorable/favorable and negative/positive $\left(\alpha=0.96 ; M_{\text {shadow }}=4.26\right.$ vs $M_{\text {no-shadow }}=4.61$, $F(1,49)=0.89, p=0.35$ ) (Janiszewski, 1990). Gender and age had no effect on the outcome measures for any study, hence not discussed further.

A second pretest using a similar one factor (product's shadow: present vs absent) between-subjects design was conducted, but with an equal mix of experiential and functional brand claims presented to the left of the product's image $\left(n=60, M_{\text {age }}=32,42 \%\right.$ females, compensation $=\$ 0.15)$. Three functional claims were randomly mixed in with 
three experiential claims. In addition to completing the ad and brand evaluation measures, participants were requested to sort each claim into a broad category: experiential (defined as aesthetic, pleasurable and enjoyable) or functional (defined as useful, practical and functional) (Park et al., 1986, 1991; Ramaseshan and Tsao, 2007). The ad ratings, measured on a 7-point scale - very bad/very good $\left(M_{\text {shadow }}=4.87\right.$ vs $M_{\text {no-shadow }}=5.00, F(1,58)=0.195$, $p=0.66)$, and the overall brand-image perceptions as a 7-point index score - useless/useful, impractical/practical, non-functional/functional, non-enjoyable/enjoyable, not visually aesthetic/visually aesthetic and not pleasurable/pleasurable $\left(\alpha=0.93 ; M_{\text {shadow }}=4.53\right.$ vs $M_{\text {no- }}$ shadow $=4.56, F(1,58)=0.012, p=0.91)$ were no-different across conditions (Park et al., 1986, 1991; Keller et al., 2011; Low and Lamb Jr., 2000; Ramaseshan and Tsao, 2007).

A chi-square test of proportions on the respondent groupings of claims under experiential and functional groups, respectively, was significant $\left(\chi^{2}(1,59)=47.22, p<\right.$ 0.01). $72 \%$ of respondents categorized experiential claims under the experiential group (43 out of 60 ), and $90 \%$ of respondents categorized the specific functional claims under the functional group (54 out of 60). Therefore, the chosen claims could be used in the main study to communicate experiential versus functional brand-images, orthogonally. Overall, combined results from pretests 1 and 2 lend support to the equal plausibility of the chosen stimulus as being promoted by an experiential or a functional brand. There was no effect of the shadow's presence on ad or brand evaluations, neither when there were no specific brand claims to anchor the visual, nor when an equal number of experiential and functional claims were listed. Therefore, any effects emerging in the main study can only be explained by the complementarity between the brand-concept, and the product shadow's presence or absence.

\section{Manipulation check}

A total of 142 subjects $\left(M_{\text {age }}=34,42 \%\right.$ females) participated in the main study (compensation $=\$ 0.20$ ). The experimental procedure employed a full 2 (product shadow: present vs absent) x 2 (brand-concept: experiential vs functional) between-subjects design, with the ad consisting of the pretested brand name ('Covi'), brand claims (experiential vs functional), and the product's picture (with shadow or without shadow) as the ad elements (see Appendix 4). Following the ad exposure, subjects completed measures on ad ratings; brand evaluations $(\alpha=0.96)$; contribution of brand claims towards experiential brandimage $(\alpha=0.97)$, and functional brand-image $(\alpha=0.92)$, respectively (to test the strength of manipulation); picture's abstractness (the explicit construal measure); brand familiarity, and finally a free recall for the shadow's presence in the ad shown before (Alter and Oppenheimer, 2008; Janiszewski, 1990; Low and Lamb Jr., 2000; Mukherjee and Hoyer, 2001; Ramaseshan and Tsao, 2007; Sujan and Bettman, 1989) (see Appendix 5 for details on the focal measures). Four participants failed an attention check set-up towards the end of the survey, and hence excluded from the final response set $(n=138)$.

A 2 (product shadow: present vs absent) X 2 (brand-concept: experiential vs functional) ANCOVA on the verbal brand claims' contribution to the experiential brandimage (with the brand claims' contribution to functional image as a covariate), revealed only a main effect of brand-concept $(F(1,133)=42.52, p<0.001)^{4}$. Experiential brand- 
image was rated higher in experiential than in the functional condition $\left(M_{\text {experiential }}=3.46 \mathrm{vs}\right.$ $\left.M_{\text {functional }}=2.39, M_{\text {difference }}=1.08, p<0.001\right)$. Similarly, an ANCOVA on the brand claims' contribution to functional image (with brand claims' contribution to experiential image as a covariate), showed that the functional brand-image was significantly stronger in the functional than the experiential condition $\left(F(1,133)=19.59, p<0.001, M_{\text {functional }}=3.44\right.$ vs $\left.M_{\text {experiential }}=2.69, M_{\text {difference }}=0.75, p<0.001\right)$. Hence the brand-concept manipulation through verbal claims (specifically) was successful.

\section{Hypotheses testing: $\mathrm{H} 2-\mathrm{H} 5$}

A 2 (product shadow: present vs absent) X 2 (brand-concept: experiential vs functional) ANOVA on the ad ratings revealed no main effects, but a significant interaction between the product's shadow and the brand-concept $\left(F(1,134)=5.145, p=0.025, \eta^{2}=0.04\right)$. Ad ratings were higher for the experiential brand in shadow's presence versus absence $\left(M_{\text {shadow }}=4.91\right.$ vs $\left.M_{\text {no-shadow }}=4.24 ; t(1,134)=2.00, p=0.05\right)$. In contrast, ad ratings were lower for the functional brand in the presence of product's shadow. However, this contrast was not significant $\left(M_{\text {shadow }}=4.28\right.$ vs $\left.M_{\text {no-shadow }}=4.68 ; t(1,134)=-1.20, p=0.23\right)$ (see Table II). Similarly, there was a significant interaction effect of shadow and brand-concept on the overall brand evaluations $\left(F(1,134)=8.826, p=0.004, \eta^{2}=0.06\right)$. Contrast between the shadow and no-shadow conditions for the experiential brand was significant and positive $\left(M_{\text {shadow }}=5.24\right.$ vs $\left.M_{\text {no-shadow }}=4.33 ; t(1,134)=2.82, p=0.005\right)$. The contrast between these conditions for the functional brand was negative, but not significant $\left(M_{\text {shadow }}=4.52\right.$ vs $M_{\text {no- }}$ shadow $=4.96 ; t(1,134)=-0.44, p=0.17$ ) (see Table II). Overall, these results support $H 2-H 3$ but not $H 4-H 5$.

\section{PLACE TABLE || ABOUT HERE}

A 2 X 2 ANOVA on the explicit construal measure for the picture's abstractness exhibited only a main effect of the brand-concept such that the product's picture was considered more abstract in the experiential, than the functional conditions (regardless of shadow's presence or absence) $(F(1,134)=6.26, p=0.01)$. The interaction term was not significant as expected, due to the implicit construal mapping of shadows in the ad frame (as identified and tested in the IAT). However, a main effect of brand-concept reveals that consumers did indeed project the product's picture to an abstract construal based on the abstract, and desirable aspects highlighted by the verbal claims in the experiential brandconcept condition, compared to the functional brand-concept condition $\left(M_{\text {experiential }}=3.71\right.$ vs. $M_{\text {functional }}=3.03, M_{\text {difference }}=0.67, p<0.05$ ).

A chi-square test of proportions on the shadow's recall measure was also significant $\left(\chi^{2}(1,137)=16.71, p<0.01\right)$. Only 30 out of 70 , i.e. $57 \%$ respondents in the shadow conditions correctly responded 'yes' to this measure, when the shadow was present. This provides further evidence towards the implicit processing of product shadows in the ad frames. Overall, study 2 provides evidence regarding differences in ad and brand evaluations, especially for the experiential brands when the product offering is showcased with (vs without) its cast shadow in the ad frame. However, the effects for the functional 
brand were only directional. An elaboration on this, as well as support for the functional brand scenario from study 3 is provided later in the discussion section.

\section{Study 3}

Study 1 provides evidence towards implicit shadow-construal mapping, and study 2 shows the lack of explicit effects on product picture's abstractness or the construal measure. However, if the presence (or absence) of shadow in the ad frame is more fitting with a specific brand construal (i.e. experiential vs functional), we should be able to see their effect on a more downstream, processing fluency measure. Changes in fluency can be measured explicitly (as opposed to probing the role of product shadows by asking regarding picture's abstractness) and hence, used for mediation testing. Therefore, in study 3, reemploying the pre-tested stimuli from study 2, another 139 MTurkers (fresh sample based on MTurk ID as a screening criteria) participated for compensation ( $M_{\text {age }}=34,48 \%$ females, \$0.20). Study 3 also employed a 2 (product shadow: present vs absent) X 2 (brandconcept: experiential vs functional) between-subjects design, followed by measures on ad ratings, brand evaluations, as well as ease of product evaluation based on the ad (Labroo et al., 2008; Landwehr et al., 2011; Lee and Aaker, 2004; Song and Schwarz, 2008a,b) (see Appendix 5).

\section{Hypotheses testing: H6-H9}

$2 \times 2$ ANOVAs on the ad ratings and overall brand evaluation ( $\alpha=.97)$ replicated the findings from study 2 . The interaction term between product shadow and brand-concept was marginally significant for the ad ratings $\left(F(1,135)=2.86, p=0.093, \eta^{2}=0.02\right)$, and significant for the overall brand evaluations $\left(F(1,135)=4.573, p=0.034, \eta^{2}=0.03\right)$. A $2 \mathrm{x}$ 2 ANOVA on the ease of product evaluation based on the ad also revealed a significant cross-over interaction $\left(F(1,135)=10.343, p=0.002, \eta^{2}=0.07\right)$, such that in the experiential condition, the ease of processing was higher in the shadow compared to the noshadow condition $\left(M_{\text {shadow }}=5.09\right.$ vs $\left.M_{\text {no-shadow }}=4.09, t(135)=2.58, p=0.01\right)$. In contrast, for the functional brand, the ease of product evaluation was lower in the shadow versus the no-shadow condition $\left(M_{\text {shadow }}=4.22\right.$ vs $\left.M_{\text {no-shadow }}=4.97, t(135)=-1.96, p=0.05\right)$ (See Table II).

More importantly, ease of product evaluation significantly mediated the interactions (Model 8, 5,000 iterations, 95\% bias-corrected CIs, Hayes, 2012). In the experiential condition, presence (vs absence) of the product's shadow enhanced the overall ad ratings by improving the ease of product evaluation (Indirect effect $=0.3622, C I=0.0956,0.7694$ ). In contrast, for the functional brand, presence (vs absence) of shadow lowered the ad ratings by decreasing the ease of product evaluation (Indirect effect $=-0.2699, C I=-0.6032$, -0.0135) (Hayes, 2009; 2013; Zhao et al., 2010). Similarly, presence (vs absence) of the product's cast shadow improved the evaluations for an experiential brand, based on a greater ease of product evaluation (Indirect effect $=0.2823, C I=0.0738,0.6520$ ). But, it hurt the evaluations for the functional brand by lowering the ease of product evaluation (Indirect effect $=-0.2104, C I=-0.5253,-0.0192$ ). Overall, these findings lend support to both $H 6-H 7$, as well as $H 8-H 9$. 


\section{Discussion}

Early depictions of shadows in art were used to enhance realism, while the latter depictions were used to dramatize a composition's surrealism (Mamassian, 2008). Visual art and perception literatures emphasize the constructive role of object shadows in shape recovery, and spatial orientation (Casati, 2004; Mamassian, 2004). On the other hand, a stream of visual cognition literature identifies certain scenarios where object shadows act as visual noise, and lower performance (Rensink and Cavanagh, 2004). In the marketing context, incorporating a product's shadow in the ad frame has long been at the discretion of the art or the creative director; to either highlight the product, or to create a dramatic brand representation. While, varied literature streams present mixed views on shadows, advertising motives for using them have largely been subjective.

This research attempts to systematically test how product shadows affect a consumer's brand perceptions. It is interesting that when explicitly probed for, general perceptions about products presented with shadows are positive, as found in the follow-up to study 1 . However, given a specific brand-concept (experiential vs functional) consumers show enhanced (or lowered) ad as well as brand evaluations given the presence (vs absence) of a product's shadow in the ad frame. This research establishes that implicit shadow processing in frames communicating an experiential brand-image versus a functional brand-image, lead to differential evaluations. It triangulates implicit and explicit methods to provide evidence for the proposed relationships. Through IAT, it finds support for the implicit mapping of product shadows to specific processing construals. Further, it supports that product shadows change brand's evaluations, through changes in processing fluency of the ad elements. Presence of a product's cast shadow is congruent with an abstract construal, while its absence maps better to a concrete construal. Therefore, an experiential brand benefits from the presence of a product's cast shadow, as elucidated by a greater ease of product evaluation. In contrast, there is evidence of decline in a functional brand's evaluation in the shadow's presence due to a lowered ease of evaluation.

The direct effects of presence (vs absence) of a product's shadow in a functional brand's frame could not be supported (H4-H5). This could be due to a greater focus on the verbal claims in such brand-concepts, as they are intended to solve consumer problems (Edell and Staelin, 1983; Park et al., 1986, 1991; Pieters and Wedel, 2004). Limitations and challenges in testing the proposed relationships arise not only from the implicit nature of shadow processing, but also from delineating the effects of cast shadows from other ad elements (i.e. brand name, claims and product's picture). However, there was a main effect, and a subsequent mediation effect based on ease of product evaluation on ad and brand perceptions for the functional brand in study 3 (H8-H9). Future studies can be designed to retest the proposed relationships using different product categories, and identifying if shadows act as visual noise in functional frames, contingent upon greater focus on the visual ad elements or conditions of higher visual complexity. Nonetheless, these studies provide novel and interesting insights with respect to consumer processing of product shadows in brand frames. 
The brand-concept to brand-image relationship thrives on communication consistency across promotional activities (Keller et al., 2011). The current work builds upon strategic brand research by suggesting brand-consistent advertising through incorporation (or omission) of peripheral elements such as product shadows. Contingent upon literature findings from visual art, visual cognition, psychophysics, perception, as well as social-behavioral sciences, it augments prior work testing Construal Level Theory (CLT) as well as Processing Fluency Models (PFMs) in advertising and brand research (Kardes et al., 2006; Lee and Labroo, 2004; Monga and John, 2010). The impact of this research spans not only print advertising but online, in-store and thus, any form of visual promotion undertaken by a brand.

Prestige brands use negative (or white) space in their promotions to inspire consumers, and make them reflect on their sophisticated brand-image (Ambler and Hollier, 2004; Olsen et al., 2012). However, there are cost implications to such designs. This research suggests that subtle, visual design elements such as cast shadows can be used instead of white space to convey similar brand perceptions (e.g. product aesthetics), thereby reducing advertising costs. In other cases, omitting shadows can not only save space, but also convey the brand-image more clearly and effectively (i.e. functional contexts).

There are many future avenues to the current research including evaluative differences based on the type of shadows, such as cast versus attached (when an object obstructs a part of light falling on itself), light versus dark, and single versus multiple shadows (Casati, 2004; Mamassian et al., 1998). Shadow are also seen cast by other brand elements such as the brand name or logo, and this provides another fruitful area for exploration (Henderson and Cote, 1998). Because it was a first such attempt, the stimuli used in the current research was black and white so as to avoid any confounds. It would also be worthwhile to see if the perceptions change further when the focal element casting its shadow is presented in color (Gorn et al., 1997; Lee et al., 2014). Brand familiarity can moderate the effect of presence of a cast shadow in the frame due to existent brand associations, and hence investigated (Campbell and Keller, 2003). Given abundant avenues to future research, it is hoped that this endeavor will inspire further research in this area.

"Shadows appear to me to be of supreme importance in perspective, because, without them opaque and solid bodies will be ill defined; that which is contained within their outlines and their boundaries themselves will be ill-understood..." - Leonardo da Vinci

Footnote 1- Please note that symbolic brand-concepts have not been included in this paper for conceptual simplicity of the current research model. It is not to say that symbolic brand-concepts would not be influenced by the presence of product shadows, but given scope of the current project, and a conceptually clearer contrast between experiential and functional brand-concepts with respect to shadow based construal mapping, this research focuses only on these brand-concepts. Future research may explore the third dimension of symbolic brand-concepts.

Footnote 2 - It is noteworthy that shadow processing by the visual-motor system interacts with the higherlevel mental processing system to affect the overall perceptive judgments of an observer (Rensink and Cavanagh, 2004; Dee and Santos, 2011). In other words, shadow-abstraction, shadow-segregation and correspondence activities interplay on both the visual and the mental-reasoning systems of an individual. 
Footnote 3 - Please note that in the current research, 'processing fluency' subsumes fluency amongst verbal, as well as visual ad elements (i.e. brand claims, product picture and product's cast shadow), and links it to higher-level mental processing (i.e. ad and brand evaluations).

Footnote 4 - It can be argued that a brand-concept could be both experiential as well as functional. Hence to maintain the independence of these two brand-concepts in the verbal claims, ANCOVA was used instead of ANOVA to test for the strength of manipulation. Given that even after including the other brand-concept in the model, each of the manipulated concept only revealed a main effect of that focal concept, these manipulation checks were cleanly validated.

\section{References}

Alter, A. L., Oppenheimer, D. M., Epley, N. and Eyre, R. N. (2007), "Overcoming intuition: metacognitive difficulty activates analytic reasoning", Journal of Experimental Psychology: General, Vol. 136 No. 4, pp. 569-576.

Ambler, T. and Hollier, E. A. (2004), "The waste in advertising is the part that works", Journal of Advertising Research, Vol. 44 No. 04, pp. 375-389.

Ang, S. H. and Lim, E. A. C. (2006), "The influence of metaphors and product type on brand personality perceptions and attitudes", Journal of Advertising, Vol. 35 No. 2, pp. 3953.

Berlyne, D. E. (1974), Studies in the new experimental aesthetics: Steps toward an objective psychology of aesthetic appreciation, Hemisphere Publishing Corporation, John Wiley \& Sons, New York, NY.

Campbell, M. C. and Keller, K. L. (2003), "Brand familiarity and advertising repetition effects", Journal of Consumer Research, Vol. 30 No. 2, pp. 292-304.

Casati, R. (2004), "The shadow knows: a primer on the informational structure of cast shadows", Perception, Vol. 33 No. 11, pp. 1385-1396.

Castiello, U., Paulignan, Y. and Jeannerod, M. (1991), "Temporal dissociation of motor responses and subjective awareness," Brain, Vol. 114 No. 6, pp. 2639-2655.

Cavanagh, P. and Leclerc, Y. G. (1989), "Shape from shadows," Journal of Experimental Psychology: Human Perception and Performance, Vol. 15 No. 1, pp. 3-27.

Clayton, M. and Heo, J. (2011), "Effects of promotional-based advertising on brand associations," Journal of Product \& Brand Management, Vol. 20 No. 4, pp. 309-315.

Cohen, J. (1992), "A power primer," Psychological Bulletin, Vol. 112 No. 1, pp. 155-159.

Dee, H. M. and Santos, P. E. (2011), "The perception and content of cast shadows: an interdisciplinary review," Spatial Cognition \& Computation, Vol. 11 No. 3, pp. 226253.

Dobni, D. and Zinkhan, G. M. (1990), "In search of brand image: A foundation analysis," In Advances in Consumer Research," Vol. 17, pp. 110-119.

Edell, J. A. and Staelin, R. (1983), "The information processing of pictures in print advertisements," Journal of Consumer Research, Vol. 10 No. 1, pp. 45-61.

Faircloth, J. B., Capella, L. M. and Alford, B. L. (2001), "The effect of brand attitude and brand image on brand equity," Journal of Marketing Theory and Practice, Vol. 9 No. 3, pp. 61-75.

Goodman, J. K. and Irmak, C. (2013), "Having versus consuming: failure to estimate usage 
frequency makes consumers prefer multifeature products," Journal of Marketing Research, Vol. 50 No. 1, pp. 44-54.

Gorn, G. J., Chattopadhyay, A., Yi, T. and Dahl, D. W. (1997), "Effects of color as an executional cue in advertising: They're in the shade," Management Science, Vol. 43 No. 10, pp. 1387-1400.

Greenwald, A. G., McGhee, D. E. and Schwartz, J. L. (1998), "Measuring individual differences in implicit cognition: the implicit association test," Journal of Personality and Social Psychology, Vol. 74 No. 6, pp. 1464-1480.

Greenwald, A. G., Nosek, B. A. and Banaji, M. R. (2003), "Understanding and using the implicit association test: I. An improved scoring algorithm," Journal of Personality and Social Psychology, Vol. 85 No. 2, pp. 197-216.

Hayes, A.F., (2009), "Beyond Baron and Kenny: Statistical mediation analysis in the new millennium," Communication Monographs, Vol. 76 No. 4, pp.408-420.

Hayes, A.F., (2012), "PROCESS: A versatile computational tool for observed variable mediation, moderation, and conditional process modeling," White Paper, Retrieved from http://www.afhayes.com/public/process2012.pdf

Hayes, A.F., (2013), Introduction to mediation, moderation, and conditional process analysis: A regression-based approach, Guilford Press.

Henderson, P. W. and Cote, J. A. (1998), "Guidelines for selecting or modifying logos," The Journal of Marketing, Vol. 62 No. 2, pp. 14-30.

Holbrook, M. B. (1986), "Aims, concepts, and methods for the representation of individual differences in esthetic responses to design features," Journal of Consumer Research, Vol. 13 No. 3, pp. 337-347.

Jacobson, J. and Werner, S. (2004), "Why cast shadows are expendable: Insensitivity of human observers and the inherent ambiguity of cast shadows in pictorial art," Perception, Vol. 33 No. 11, pp. 1369-1383.

Janiszewski, C. (1990), "The influence of print advertisement organization on affect toward a brand name," Journal of Consumer Research, Vol. 17 No. 1, pp. 53-65.

Kardes, F. R., Cronley, M. L. and Kim, J. (2006), "Construal-level effects on preference stability, preference-behavior correspondence, and the suppression of competing brands," Journal of Consumer Psychology, Vol. 16 No. 2, pp. 135-144.

Keller, K. L. (1993), "Conceptualizing, measuring, and managing customer-based brand equity," The Journal of Marketing, Vol. 57 No. 1, pp. 1-22.

Keller, K. L., Parameswaran, M. and Jacob, I. (2011), Strategic brand management: Building, measuring, and managing brand equity, Pearson Education, India.

Labroo, A. A., Dhar, R. and Schwarz, N. (2008), "Of frog wines and frowning watches: Semantic priming, perceptual fluency, and brand evaluation," Journal of Consumer Research, Vol. 34 No. 6, pp. 819-831.

Landwehr, J. R., Labroo, A. A. and Herrmann, A. (2011), "Gut liking for the ordinary: Incorporating design fluency improves automobile sales forecasts," Marketing Science, Vol. 30 No. 3, pp. 416-429.

Lee, A. Y. (2002), "Effects of implicit memory on memory-based versus stimulus-based 
brand choice," Journal of Marketing Research, Vol. 39 No. 4, pp. 440-454.

Lee, A. Y. and Aaker, J. L. (2004), "Bringing the frame into focus: the influence of regulatory fit on processing fluency and persuasion," Journal of Personality and Social Psychology, Vol. 86 No. 2, pp. 205-218.

Lee, A. Y. and Labroo, A. A. (2004), "The effect of conceptual and perceptual fluency on brand evaluation," Journal of Marketing Research, Vol. 41 No. 2, pp. 151-165.

Lee, H., Deng, X., Unnava, H. R. and Fujita, K. (2014), "Monochrome forests and colorful trees: the effect of black-and-white versus color imagery on construal level," Journal of Consumer Research, Vol. 41 No. 4, pp. 1015-1032.

Liberman, N. and Trope, Y. (1998), "The role of feasibility and desirability considerations in near and distant future decisions: A test of temporal construal theory," Journal of Personality and Social Psychology, Vol. 75 No. 1, pp. 5-18.

Liberman, N., Trope, Y. and Wakslak, C. (2007), "Construal level theory and consumer behavior," Journal of Consumer Psychology, Vol. 17 No. 2, pp. 113-117.

Liu, W. (2008), "Focusing on desirability: The effect of decision interruption and suspension on preferences," Journal of Consumer Research, Vol. 35 No. 4, pp. 640652.

Low, G. S. and Lamb Jr, C. W. (2000), "The measurement and dimensionality of brand associations," Journal of Product \& Brand Management, Vol. 9 No. 6, pp. 350-370.

Mamassian, P. (2008), "Ambiguities and conventions in the perception of visual art," Vision Research, Vol. 48 No. 20, pp. 2143-2153.

Mamassian, P. (2004), "Impossible shadows and the shadow correspondence problem," Perception, Vol. 33 No. 11, pp. 1279-1290.

Mamassian, P., Knill, D. C. and Kersten, D. (1998), "The perception of cast shadows," Trends in Cognitive Sciences, Vol. 2 No. 8, pp. 288-295.

Martin, I. M. and Stewart, D. W. (2001), "The differential impact of goal congruency on attitudes, intentions, and the transfer of brand equity," Journal of Marketing Research, Vol. 38 No. 4, pp. 471-484.

Meenaghan, T. (1995), "The role of advertising in brand image development," Journal of Product \& Brand Management, Vol. 4 No. 4, pp. 23-34.

Monga, A. B. and John, D. R. (2010), "What makes brands elastic? The influence of brand concept and styles of thinking on brand extension evaluation," Journal of Marketing, Vol. 74 No. 3, pp. 80-92.

Mukherjee, A. and Hoyer, W. D. (2001), "The effect of novel attributes on product evaluation," Journal of Consumer Research, Vol. 28 No. 3, pp. 462-472.

Nosek, B. A., Greenwald, A. G. and Banaji, M. R. (2005), "Understanding and using the Implicit Association Test: II. Method variables and construct validity," Personality and Social Psychology Bulletin, Vol. 31 No. 2, pp. 166-180.

Olsen, G. D., Pracejus, J. W. and O'Guinn, T. C. (2012), "Print advertising: White space," Journal of Business Research, Vol. 65 No. 6, pp. 855-860.

Park, C. W., Jaworski, B. J. and Maclnnis, D. J. (1986), "Strategic brand concept-image management," The Journal of Marketing, Vol. 50 No. 4, pp. 135-145. 
Park, C. W., Milberg, S. and Lawson, R. (1991), "Evaluation of brand extensions: the role of product feature similarity and brand concept consistency," Journal of Consumer Research, Vol. 18 No. 2, pp. 185-193.

Pieters, R. and Wedel, M. (2004), "Attention capture and transfer in advertising: Brand, pictorial, and text-size effects," Journal of Marketing, Vol. 68 No. 2, pp. 36-50.

Ramaseshan, B. and Tsao, H.-Y. (2007), "Moderating effects of the brand concept on the relationship between brand personality and perceived quality," Journal of Brand Management, Vol. 14 No. 6, pp. 458-466.

Rensink, R. A. and Cavanagh, P. (2004), "The influence of cast shadows on visual search," Perception, Vol. 33 No. 11, pp. 1339-1358.

Shannon, C. E. (1949), "Communication in the presence of noise," Proceedings of the IRE, Vol. 37 No. 1, pp. 10-21.

Sheng Goh, Y., Chattaraman, V. and Forsythe, S. (2013), "Brand and category design consistency in brand extensions," Journal of Product \& Brand Management, Vol. 22 No. 4, pp. 272-285.

Song, H. and Schwarz, N. (2008a), "Fluency and the detection of misleading questions: Low processing fluency attenuates the Moses illusion," Social Cognition, Vol. 26 No. 6, pp. 791-799.

Song, H. and Schwarz, N. (2008b), "If it's hard to read, it's hard to do processing fluency affects effort prediction and motivation," Psychological Science, Vol. 19 No. 10, pp. 986-988.

Sujan, M. and Bettman, J. R. (1989), "The effects of brand positioning strategies on consumers' brand and category perceptions: Some insights from schema research," Journal of Marketing Research, Vol. 26 No. 4, pp. 454-467.

Thorbjørnsen, H. (2005), "Brand extensions: brand concept congruency and feedback effects revisited," Journal of Product \& Brand Management, Vol. 14 No. 4, pp. 250257.

Till, B. D. and Busler, M. (2000), "The match-up hypothesis: Physical attractiveness, expertise, and the role of fit on brand attitude, purchase intent and brand beliefs," Journal of Advertising, Vol. 29 No. 3, pp. 1-13.

Trope, Y. and Liberman, N. (2010), "Construal-level theory of psychological distance," Psychological Review, Vol. 117 No. 2, pp. 440-463.

Wedel, M. and Pieters, R. (2012) (Eds), Visual marketing: From attention to action, Psychology Press.

Zhao, X., Lynch, J.G. and Chen, Q., (2010), "Reconsidering Baron and Kenny: Myths and truths about mediation analysis," Journal of Consumer Research, Vol. 37 No. 2, pp.197-206. 
Table | IAT orders with mean $D$ values and standard deviations (in parentheses) from Study 1

\begin{tabular}{|c|c|c|c|c|}
\hline Initial target concept presentation order & Target concept-attribute pairing order & $\mathbf{n}$ & Mean $D$ & SD \\
\hline Abstract on left (concrete on right) & Compatible before incompatible & 36 & 0.2462 & 0.6484 \\
\hline Concrete on left (abstract on right) & Compatible before incompatible & 38 & 0.1380 & 0.8476 \\
\hline Abstract on left (concrete on right) & Incompatible before compatible & 36 & -0.0472 & 0.6682 \\
\hline \multirow[t]{2}{*}{ Concrete on left (abstract on right) } & Incompatible before compatible & 34 & -0.0996 & 0.6239 \\
\hline & All & 144 & & \\
\hline & & \multicolumn{3}{|c|}{$D_{\text {absolute }}=0.1327^{*}$} \\
\hline
\end{tabular}

$* p<0.05$ 
Table || Means and SDs of Study 2 and Study 3

\begin{tabular}{llccccccc}
\hline Study 2 & & \multicolumn{4}{c}{ Ad rating } & \multicolumn{2}{c}{ Brand evaluation } & \multicolumn{2}{c}{ Construal (Picture) } \\
Brand-concept & Condition & $\mathbf{n}$ & Mean & SD & Mean & SD & Mean & SD \\
\hline \multirow{2}{*}{ Experiential } & Shadow & 34 & 4.91 & 1.36 & 5.24 & 1.30 & 3.65 & 1.50 \\
& No-shadow & 34 & 4.24 & 1.50 & 4.33 & 1.42 & 3.76 & 1.69 \\
\multirow{3}{*}{ Functional } & Shadow & 36 & 4.28 & 1.28 & 4.52 & 1.27 & 2.83 & 1.60 \\
& No-shadow & 34 & 4.68 & 1.43 & 4.96 & 1.33 & 3.24 & 1.52 \\
& All & 138 & & & & & & \\
\hline
\end{tabular}

\begin{tabular}{llccccccc}
\hline Study 3 & \multicolumn{9}{c}{ Ad rating } & \multicolumn{2}{c}{ Brand evaluation } & \multicolumn{2}{c}{ Processing fluency } \\
Brand-concept & Condition & n & Mean & SD & Mean & SD & Mean & SD \\
\hline \multirow{2}{*}{ Experiential } & Shadow & 33 & 4.64 & 1.17 & 5.03 & 1.21 & 5.09 & 1.55 \\
& No-shadow & 35 & 4.03 & 1.65 & 4.47 & 1.63 & 4.09 & 1.70 \\
& Shadow & 36 & 3.94 & 1.59 & 4.10 & 1.43 & 4.22 & 1.61 \\
& No-shadow & 35 & 4.17 & 1.34 & 4.59 & 1.43 & 4.97 & 1.56 \\
& All & 139 & & & & & & \\
\hline
\end{tabular}




\section{APPENDIX 1}

Real World Ad-Imagery incorporating product shadows - Apple's iWatch with product shadow (top-left) vs competitor Android Smart-watch without product shadow (top-right), Omega's Men's Watch (bottom-left) and Samsung Galaxy Camera (bottom-right)
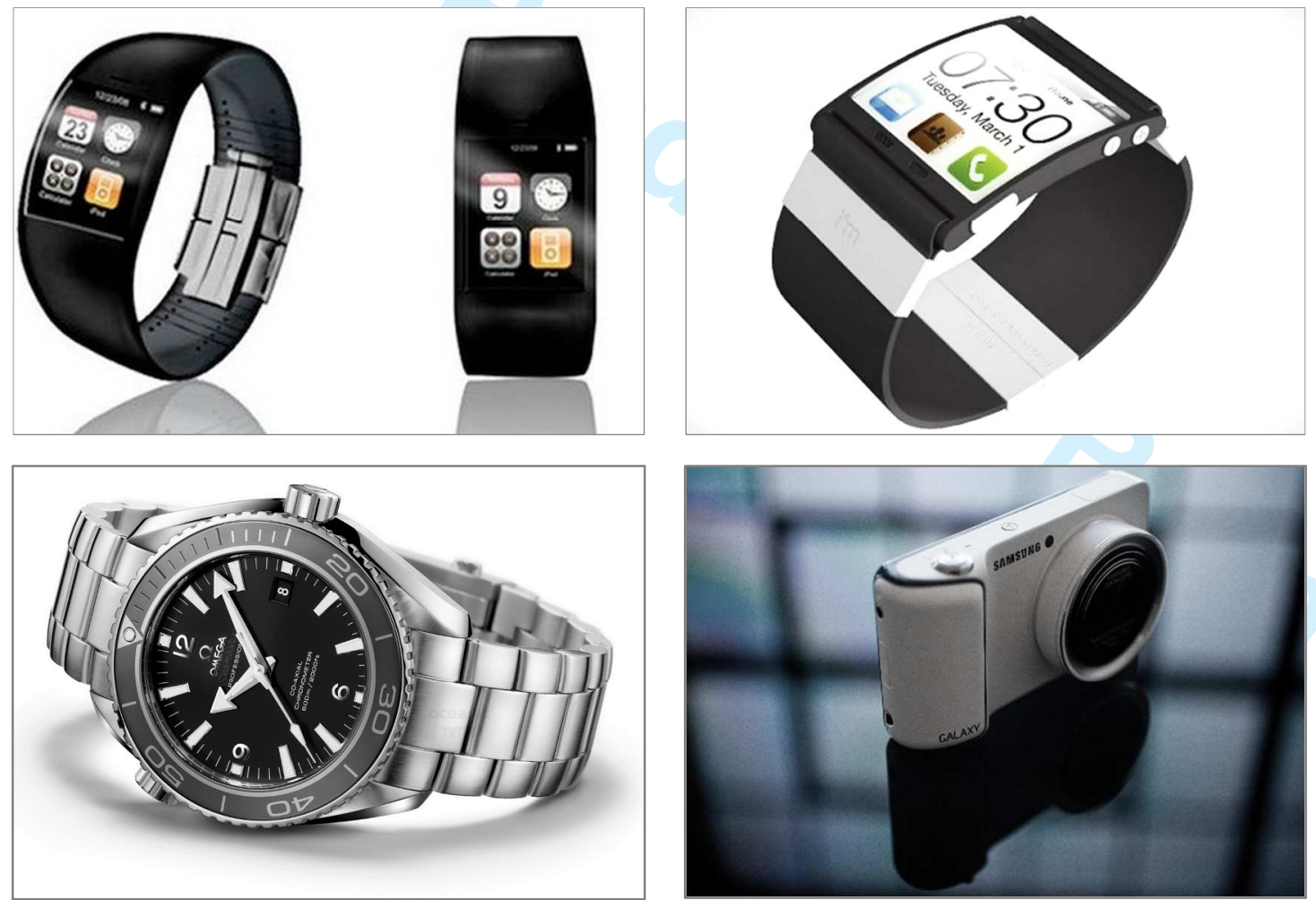


\section{APPENDIX 2}

Study 1 IAT Stimuli and Scripts

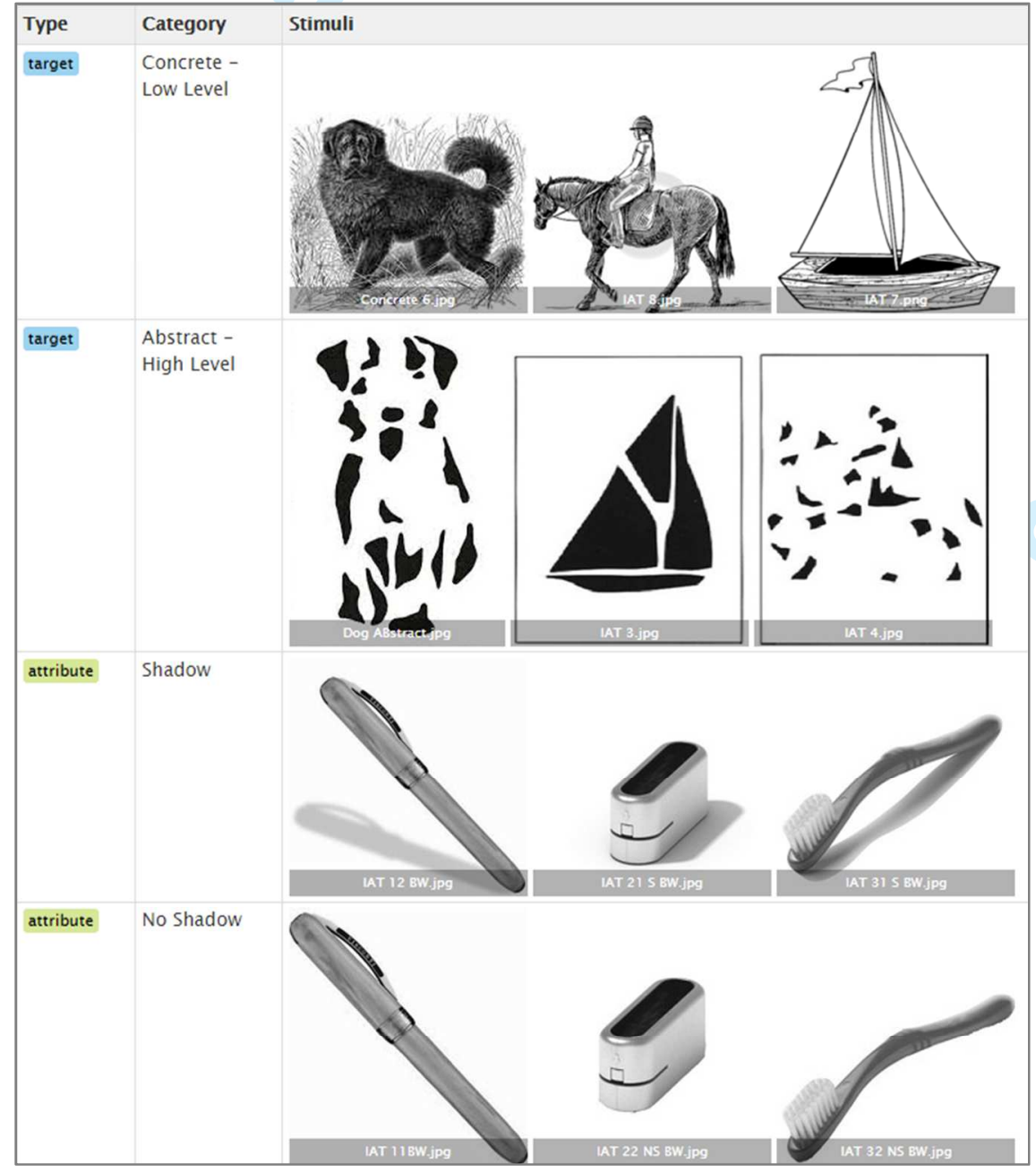

MTurk Script - This test is designed to understand some implicit associations that people might have. We have some predefined categories in this test. For instance, 'abstract or high level' refers to a more super-ordinate or broad perspective which considers the whole rather than the parts. 'Concrete or low level' refers to subordinate or detailed perspective which considers low level parts. Please follow the instructions on the next page to take this test.

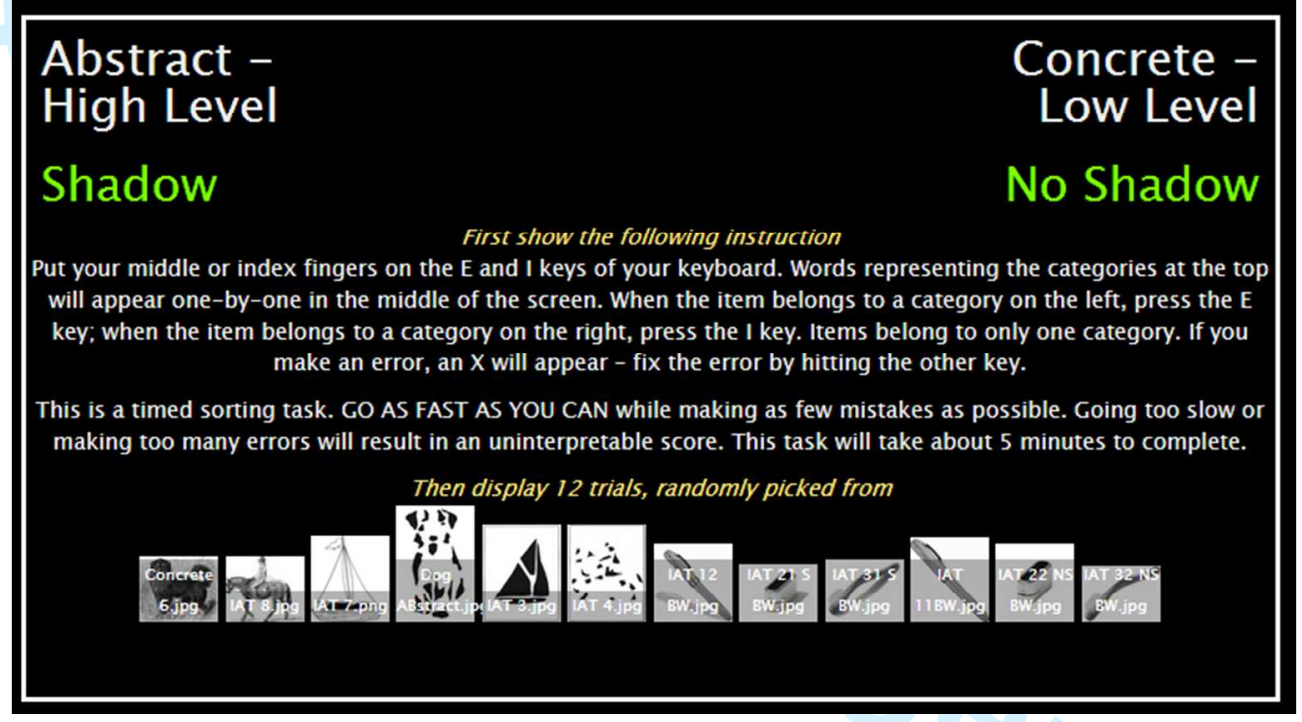




\section{APPENDIX 3}

Study 1 IAT Administration sequence for an individual and $D$ calculation

\begin{tabular}{|l|l|c|c|}
\hline & Trial Set & $\begin{array}{c}\text { Tags } \\
\text { (Example from one of the four scenarios) }\end{array}$ & $\begin{array}{c}\text { Number of trails } \\
\text { (Images classified) }\end{array}$ \\
\hline Stage 1 & Set 1 - Target Practice & Abstract/Concrete & 6 \\
\hline Stage 2 & Set 2 - Attribute Practice & Shadow/No-Shadow & 6 \\
\hline Stage 3 & Set 3 - Compatible Test 1 & Abstract-Shadow/Concrete-No-Shadow & 12 \\
\hline Stage 4 & Set 4 - Compatible Test 2 & Same as above & 12 \\
\hline Stage 5 & Set 5 - Reversed Target Practice & Concrete/Abstract & 6 \\
\hline Stage 6 & Set 6 - Incompatible Test 1 & Shadow/No-Shadow & 12 \\
\hline Stage 7 & Set 7 - Incompatible Test 2 & Concrete-Shadow/Abstract-No-Shadow & 12 \\
\hline
\end{tabular}

Calculation of the $D$ Measure

$\mathrm{MD}_{1}=$ MRLStage $6-\mathrm{MRL}_{\text {Stage }} 3$

$\mathrm{MD}_{2}=$ MRLStage7 - MRLStage 4

Inclusive $\mathrm{SD}_{1}=\left(\mathrm{SD}_{\text {Stage } 6}+\mathrm{SD}_{\text {Stage }} 3\right) / 2$

Inclusive $\mathrm{SD}_{2}=\left(\mathrm{SD}_{\text {Stage }} 7+\mathrm{SD}_{\text {Stage }} 4\right) / 2$

$\mathrm{MD}_{\mathrm{Adj} 1}=\mathrm{MD}_{1} /$ Inclusive $\mathrm{SD}_{1}$

$\mathrm{MD}_{\mathrm{Adj} 2}=\mathrm{MD}_{2} /$ Inclusive $\mathrm{SD}_{2}$

$D=\left(\mathrm{MD}_{\mathrm{Adj} 1}+\mathrm{MD}_{\mathrm{Adj} 2}\right) / 2$

Notes: Where, MD - Mean Difference; MRL - Mean Response Latency in milliseconds; SD - Standard Deviation; MDAdj - Mean Difference adjusted by standard deviation. The count of incorrect responses was used to penalize the mean response latency for each set of trials, using the formula "stage mean + twice the SD of correct responses for that set" (Greenwald et al., 2003). Also note that the only difference between $D$ and Cohen's $d$ is that computation of $D$ ignores condition membership of each score by using standard deviations from both stages in the denominators (Cohen, 1992; Greenwald et al., 2003). 


\section{APPENDIX 4}

Stimuli for Study 2 and Study 3 (Top-left - Experiential/Shadow, Top-right - Experiential/No Shadow, Bottom-left Functional/Shadow and Bottom-right - Functional/No-Shadow)
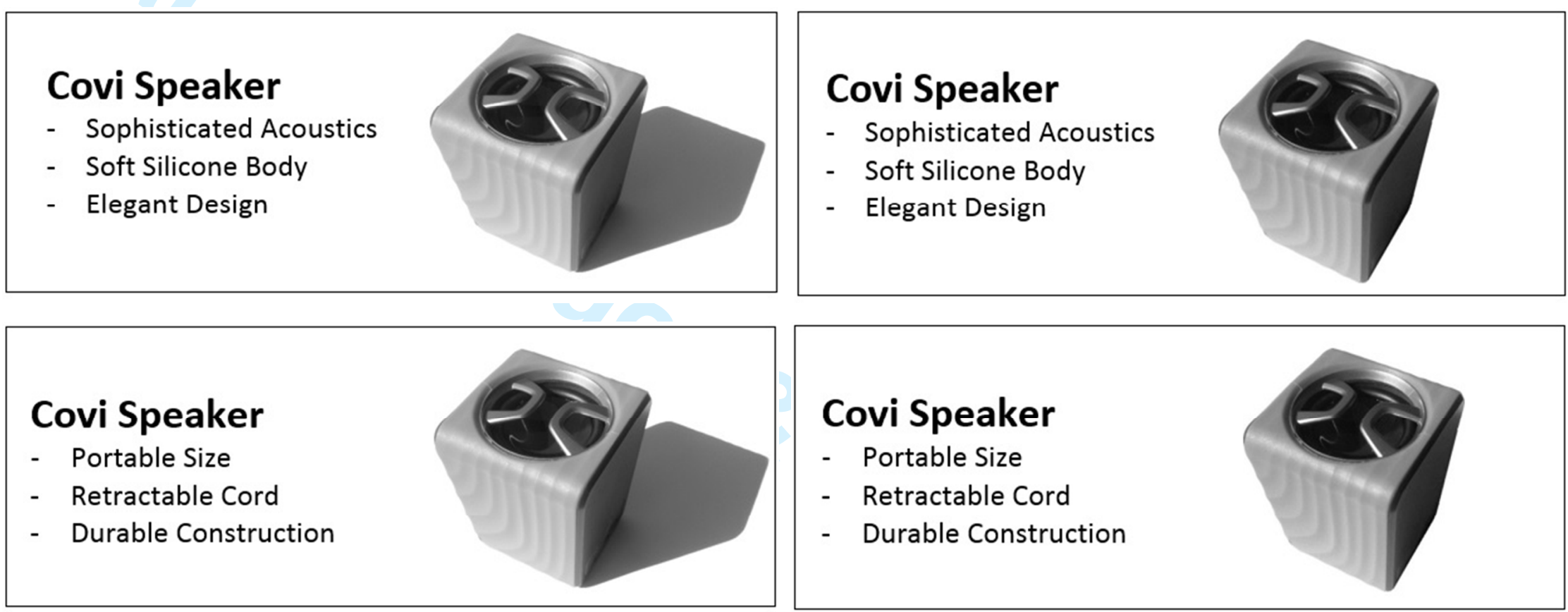

Notes: Grey-scale images were used to avoid any color based confounds, and to ensure that the manipulations were clean i.e. based only on changes in brand image and presence/absence of the product's cast shadow. Covi is an Auckland based insurance company and hence, unknown to the U.S. demographic. Please refer the Target website link for the original product description and brand claims - (http://www.target.com/p/hmdx-burst-wireless-portable-speaker-assorted-colors/-/A$\underline{14533788)}$ 


\section{APPENDIX 5}

\section{Focal measures used in Study 2 and Study 3}

Overall ad rating: $1=$ very bad, 7 = very good

Overall brand evaluation $(\alpha=0.96)$

$1=$ bad, $7=$ good

$1=$ dislike, $7=$ like

1 = unfavorable, 7 = favorable

$1=$ negative, $7=$ positive

Brand image contribution through claims

- Extent to which the brand claims are descriptive of the following brand dimensions: 1= far too little, $5=$ quite a lot

\begin{tabular}{ll} 
Experiential $(\alpha=0.97)$ & Functional $(\alpha=0.92)$ \\
\hline Visual Aesthetics & Usefulness \\
Visual Appeal & Practicality \\
Visual Pleasantness & Functionality
\end{tabular}

Picture abstractness

- Please rate the concreteness/abstractness of the product's picture shown in the ad.: $1=$ very concrete, $7=$ very abstract

Ease of product evaluation

- Please tell us how difficult/easy was it to evaluate the product based on the ad.: $1=$ very difficult, $7=$ very easy 